ISSN: $1984-6266$

\section{Índice de disclosure dos Estados brasileiros e do Distrito Federal com base nas Normas Brasileiras de Contabilidade Aplicadas ao Setor Público: uma análise da similaridade dos entes públicos.}

\author{
Mariana Camilla Coelho Silva Castro \\ UFMG - Universidade Federal de Minas Gerais \\ maricoelho2000@yahoo.com.br \\ Jacqueline Veneroso Alves da Cunha \\ UFMG - Universidade Federal de Minas Gerais \\ jvac@ufmg.br \\ Jorge Eduardo Scarpin \\ UFPR - Universidade Federal do Paraná \\ jorge.scarpin@ufpr.br \\ José Roberto de Souza Francisco \\ UFMG - Universidade Federal de Minas Gerais \\ jroberto@face.ufmg.br
}

\author{
Recebimento: \\ 06/03/2018 \\ Aprovação: \\ 22/04/2019 aprovação do artigo:
Dr. Flaviano Costa \\ Editor responsável pela
}

Editor responsável pela edição do artigo:

Dr. Flaviano Costa

\author{
Avaliado pelo sistema: \\ Double Blind Review
}

A reprodução dos artigos, total ou parcial, pode ser feita desde que citada a fonte.

\title{
Resumo
}

Neste estudo, as similaridades entre os entes públicos foram analisadas em termos de suas características econômicas, sociais e da variabilidade do Índice de Disclosure (ID), construído com base na divulgação de informações conforme as Normas Brasileiras de Contabilidade Aplicadas ao Setor Público (NBCASP). A amostra foi composta por 25 estados e pelo Distrito Federal, no exercício de 2014. Os dados foram analisados estatisticamente por meio de uma análise de clusters. O ID médio calculado para os entes foi de $76 \%$, sendo um indicativo de que o Brasil necessita evoluir para o atendimento da legislação e a prestação de informações para o controle social. A análise de clusters permitiu a divisão dos entes em quatro grupos, sugerindo que estados da mesma região podem apresentar características semelhantes, aproximando-os em relação às suas características econômicas e sociais, bem como em seu ID.

Palavras-chave: Normas Brasileiras de Contabilidade Aplicadas ao Setor Público. Processo de Convergência. Evidenciação.

DOI:

http://dx.doi.org/10.5380/rc\&c.v10i2.58271 


\title{
DISCLOSURE INDEX OF THE BRAZILIAN STATES AND THE FEDERAL DISTRICT BASED ON THE BRAZILIAN ACCOUNTING STANDARDS APPLIED TO THE PUBLIC SECTOR: AN ANALYSIS OF THE SIMILARITY OF PUBLIC ENTITIES.
}

\begin{abstract}
In this study, the similarities between public entities were analyzed in terms of the socioeconomic characteristics and the variability of a Disclosure Index (ID) that was built based on the information disclosed according to the Brazilian Accounting Standards Applied to the Public Sector (NBCASP) in 2014. The sample assessed was composed of 25 states and the Federal District. Cluster analysis were performed to analyze the data set. The ID average obtained for the Brazilian state entities was equal to $76 \%$. This result indicates that Brazil needs to improve its legislation attendance in providing quality information to the society. The cluster analysis allowed the classification of the state entities into four groups in a result that indicates that states of the same region can present similar characteristics regarding to their socioeconomic characteristics, as well as the calculated ID.
\end{abstract}

Keywords: Brazilian Accounting Standards Applied to the Public Sector; Convergence Process; Disclosure.

\section{Introdução}

A contabilidade pública vem passando por mudanças, visando torná-la mais compreensível e confiável, e também melhorar a qualidade dos seus relatórios, fornecendo informações para o controle social. Em 1977, foi criado o International Federation of Accountants (IFAC), que é uma organização mundial dedicada a servir ao interesse público por meio do fortalecimento da profissão e contribuição para o desenvolvimento de fortes economias internacionais, além de ser o responsável por emitir pronunciamentos voltados para o setor público.

O IFAC emite as normas contábeis a serem utilizadas pelos entes públicos na elaboração e divulgação de suas demonstrações financeiras. Denominadas International Public Sector Accounting Standards (IPSAS), baseiam-se nas International Financial Reporting Standards (IFRS) emitidas pelo International Accounting Standards Board (IASB) e utilizadas pelo setor privado.

A contabilidade pública tradicional, com foco estritamente no aspecto orçamentário e buscando assegurar a conformidade com os requisitos legais tem se mostrado, de modo geral, ineficiente. $O$ objeto de estudo da contabilidade, independente se aplicada ao setor público ou privado, é o patrimônio, e este deve ser reconhecido e controlado, o que não se consegue com uma contabilidade voltada estritamente ao aspecto orçamentário (Abushamsieh, López-Hernándes \& Ortiz-Rodríguez, 2014). A modernização da administração no setor público acontece para torná-la mais eficiente e eficaz no atendimento das demandas da sociedade. A introdução de ferramentas para medir o desempenho dos entes públicos reforçou a demanda por relatórios realmente informativos (Borges, 2012).

No Brasil, de acordo com Feijó (2013), várias ações estratégicas estão em curso visando à implantação de um novo modelo de contabilidade aplicada ao setor público, que tem como objetivo convergir as práticas contábeis vigentes no país ao padrão internacional de contabilidade aplicada ao setor público. Esse processo iniciou-se em 2007 com a criação do Comitê Gestor da Convergência, com o objetivo de traçar um plano de ação e coordenar o processo de convergência das normas brasileiras às internacionais nas áreas de auditoria, contabilidade pública e assuntos regulatórios. Esse Grupo Técnico teve como função inicial a tradução e validação das IPSAS e a elaboração e discussão de minutas para implantação das normas internacionais no país.

Em 2008, o Ministério da Fazenda publicou a Portaria no 184 que, de acordo com Darós e Pereira (2012), trata das diretrizes a serem observadas pelos entes públicos (abrangendo União, Estados e Municípios) 


\section{Mariana Camilla Coelho Silva Castro, Jacqueline Veneroso Alves da Cunha, Jorge Eduardo Scarpin \& José}

Roberto de Souza Francisco.

em relação aos procedimentos, práticas, elaboração e divulgação das demonstrações contábeis, de forma a torná-los convergentes com as normas internacionais de contabilidade aplicadas ao setor público. Após a publicação da Portaria, o Conselho Federal de Contabilidade (CFC) emitiu as primeiras Normas Brasileiras de Contabilidade Aplicadas ao Setor Público (NBC TSP), elaboradas de acordo com as IPSAS.

De acordo com Lima, Santana e Guedes (2009), as NBC TSP têm por objetivo contribuir para o correto reconhecimento, mensuração e evidenciação de atos e fatos administrativos com base na Teoria da Contabilidade, de forma que a contabilidade pública brasileira, além de cumprir os aspectos legais e formais, reflita a essência das transações governamentais e seu impacto no patrimônio público.

Em 2009, a Secretaria do Tesouro Nacional (STN) editou, para aplicação a partir de 2010, a primeira edição do Manual de Contabilidade Aplicada ao Setor Público (MCASP), consolidando conceitos e regras para a contabilização das variações patrimoniais sob a ótica da competência e a implantação da contabilidade patrimonial (Feijó, 2013). O MCASP é o instrumento que incorpora as regras constantes nas NBC TSP com algumas regras das IPSAS e tem como objetivo padronizar os procedimentos contábeis. Atualmente, o MCASP está em sua $7^{a}$ edição. Ele está constantemente em atualização visando simplificar sua linguagem, torná-lo mais objetivo com foco nos aspectos contábeis, bem como mantê-lo atualizado de acordo com as mudanças na legislação.

Costa (2012) destaca que, além de unificar a contabilidade para os vários ramos de seu segmento, outro fator importante é torná-la mais clara e objetiva aos seus usuários. Os principais interessados na contabilidade das instituições públicas são os contribuintes, pois, afinal, a maior parte da receita vem deles, sendo importante saber como esses recursos são administrados para melhor exercer o controle social.

A divulgação de informações por meio das demonstrações contábeis é o principal meio de controle da aplicação dos recursos públicos e se propõe a reduzir a assimetria informacional entre os gestores, a população e demais usuários da contabilidade aplicada ao setor público. Dessa forma, a evidenciação contábil ou disclosure, compõe um dos meios disponíveis para que o cidadão analise e controle como os recursos públicos estão sendo aplicados.

No âmbito da administração pública, o disclosure se destaca, uma vez que a transparência governamental é condição necessária para a efetivação de qualquer ordem democrática, tendo em vista que só há controle efetivo dos governantes se seus atos forem adequadamente informados à sociedade (Avelino, 2013). Além disso, a transparência constitui garantia da democracia no próprio controle social, bem como contribui de forma direta para a conquista da eficiência na gestão pública. Dantas, Zendersky e Niyama (2004) afirmam que a evidenciação não significa apenas divulgar, mas divulgar com qualidade, oportunidade e clareza. Para que se obtenha a transparência desejada com a evidenciação, deve-se divulgar tanto informações qualitativas quanto quantitativas, possibilitando aos usuários a compreensão das atividades desenvolvidas e a diminuição dos riscos, levando sempre em consideração a tempestividade, o detalhamento e a relevância necessários.

Em função da transparência que deve permear a gestão pública, os gestores devem informar à sociedade sobre os resultados de suas ações. Os mercados, os investidores, a sociedade e os próprios governantes para controlar, avaliar e reprogramar suas ações, necessitam de informações tempestivas e confiáveis. Pesquisas têm buscado analisar o nível de disclosure dos entes públicos, bem como identificar a existência de relação entre o nível de evidenciação e características econômicas e sociais desses entes. Nessa pesquisa, levando em consideração a dimensão territorial e as características distintas de cada região do país, buscou-se avaliar as similaridades entre os Estados brasileiros e o Distrito Federal em relação à variabilidade das características econômicas e sociais, bem como em relação ao Índice de Disclosure obtido por cada um deles.

Assim, esta pesquisa tem como objetivo verificar se os Estados brasileiros e o Distrito Federal estão adotando os procedimentos exigidos pela nova regulamentação, proporcionando à população informações importantes para o controle social, conforme previsão do artigo 74 da Constituição Federal e da Lei de 
Responsabilidade Fiscal, que tratam da transparência e da responsabilidade na gestão dos recursos públicos, bem como identificar se existem similaridades entre os entes com base em suas características sociais e econômicas, aliadas ao índice de divulgação (ID) obtido.

\section{Referencial Teórico}

\subsection{Teoria da Divulgação}

A Teoria da Divulgação analisa modelos que verificam como a divulgação de informações influencia o mercado e o desempenho econômico das empresas, e tem por objetivo explicar os motivos da divulgação da informação contábil (Corrêa, 2014).

Para Verrecchia (2001) a pesquisa sobre divulgação em contabilidade se divide em três categorias: pesquisa sobre divulgação baseada em associação (association-based disclosure), que tem como objetivo estudar os efeitos da divulgação na mudança das ações dos investidores; pesquisa sobre divulgação baseada em julgamento (discretionary-based disclosure), que buscam identificar os motivos da divulgação, verificando os incentivos que as empresas têm para divulgar; e pesquisa sobre divulgação baseada em eficiência (efficiency-based disclosure), que visam discutir que tipos de divulgação são mais eficientes ou preferidos (Salotti \& Yamamoto, 2005).

De acordo com Salotti e Yamamoto (2008), a divulgação de informações pode se dar de forma voluntária ou compulsória. A divulgação feita de forma voluntária é caracterizada por uma ação proativa da entidade, geralmente ocorrida de incentivos recebidos pelo administrador para divulgá-las, já a divulgação compulsória decorre de ação reativa, oriunda de regulamentação que obriga a entidade a divulgar informações.

No caso dos entes públicos analisados nesse estudo, a divulgação tem caráter compulsório, uma vez que é determinada por Lei, cabendo punição àqueles que não observarem os aspectos determinados. $A$ pesquisa pode ser enquadrada também na categoria das pesquisas sobre Divulgação Baseada em Julgamento, uma vez que tem como objetivo avaliar se as características econômicas e sociais, bem como o İndice de Disclosure obtido podem aproximar os entes públicos com base em suas similaridades.

\subsection{Normas Brasileiras de Contabilidade Aplicadas ao Setor Público (NBC TSP)}

Buscando promover a reforma da contabilidade aplicada ao setor público no Brasil, após a criação do Comitê Gestor da Convergência, foram publicadas as primeiras Normas Brasileiras de Contabilidade Aplicadas ao Setor Público (NBC T 16.1 a 16.10), a partir de 2008, objetivando o reconhecimento, a evidenciação e a mensuração de atos e fatos contábeis.

Desde 2008, quando as primeiras normas entraram em vigor, muitas mudanças ocorreram na legislação que trata do processo de convergência da contabilidade do setor público ao padrão internacional. Em outubro de 2016 entrou em vigor a NBC TSP Estrutura Conceitual, a primeira norma convergida às IPSAS. De acordo com o CFC (2016), a estrutura conceitual estabelece os conceitos que fundamentam a elaboração e a divulgação dos relatórios contábeis com base no regime de competência. Dentre outros assuntos, ela trouxe como principais mudanças a revogação das NBC T 16.1 a 16.5 e da Resolução n 750/1993 que tratava dos Princípios de Contabilidade, passando a serem observadas as características qualitativas da informação contábil bem como as restrições acerca dessas informações. 
Nos anos de 2016 e 2017 entraram em vigor as NBC TSP de 01 a 10 já convergidas com as normas internacionais (IPSAS), no entanto, ainda permanecem em vigor as NBC T 16.6 a 16.10 que não possuem correlação com as normas internacionais.

As NBC TSP, juntamente com o Manual de Contabilidade Aplicada ao Setor Público (MCASP), visam auxiliar o processo de elaboração e execução do orçamento, além de resgatar o objeto da contabilidade como ciência, que é o patrimônio. Com isso, a contabilidade poderá atender a demanda de informações requeridas por seus usuários, possibilitando a análise de demonstrações contábeis adequadas aos padrões internacionais, sob os enfoques orçamentário e patrimonial, com base em um Plano de Contas Nacional (STN, 2012).

De acordo com Lima et al. (2009), as NBC TSP têm como objetivo fornecer um novo arcabouço conceitual para a Contabilidade Aplicada ao Setor Público e contribuir para a uniformização de práticas e procedimentos contábeis, em virtude da dimensão e da diversidade da estrutura da Administração Pública brasileira.

De acordo com Darós e Pereira (2012) as NBC TSP trarão uma mudança no enfoque contábil, a princípio essencialmente orçamentário, se volta agora para uma contabilidade pública patrimonial, com a adoção do regime de competência para receitas e despesas públicas, passando a registrar as transações no momento da ocorrência de cada fato gerador, e não no momento do pagamento ou recebimento. Isso faz com que informações que não apareciam nas demonstrações públicas passem a ser registradas no período ao qual se relacionam (Cruvinel \& Lima, 2011).

As NBC TSP trazem mudanças que visam complementar e aprimorar a contabilidade aplicada ao setor público, reforçando de forma detalhada e por meio de suas diretrizes, aspectos que contribuam para 0 desenvolvimento das informações divulgadas pelos entes públicos.

De acordo com a Portaria $n^{0}$ 634/2013 o prazo inicial para adoção integral do Plano de Contas Aplicado ao Setor Público (PCASP), das Demonstrações Contábeis Aplicadas ao Setor Público (DCASP) e da consolidação das contas públicas dos entes da Federação se daria até o término do exercício de 2014 . Uma vez que 2014 foi o primeiro exercício cujas informações contábeis deveriam ser divulgadas conforme as novas normas, ele foi o escolhido para ser analisado neste estudo. Com isso, os prazos estabelecidos para a observância obrigatória dos novos procedimentos contábeis estão de acordo com as partes do MCASP, e são demonstrados na Figura 1.

Figura 1: Prazos para adoção do MCASP

\begin{tabular}{|c|l|}
\hline Parte & \multicolumn{1}{|c|}{ Prazo } \\
\hline PCASP & 2014 (integralmente até o final do exercício) para União, Estados, DF e Municípios \\
\hline DCASP & 2014 (integralmente até o final do exercício) para União, Estados, DF e Municípios \\
\hline PCP & $\begin{array}{l}\text { Prazos a serem definidos conforme ato normativo específico da STN para cada } \\
\text { procedimento }\end{array}$ \\
\hline PCE & 2013 para União, Estados, DF e Municípios \\
\hline PCO & Aplicabilidade imediata \\
\hline Consolidação das Contas & $2014 / 2015$ com adoção integral do PCASP e das DCASP \\
\hline
\end{tabular}

Fonte: Nota Técnica n 5/2013 (STN, 2013).

Gava (2013) afirma que o MCASP é o primeiro manual voltado especificamente à área pública, servindo de referência para os procedimentos contábeis a serem adotados pelos entes e serve de elo entre a parte conceitual e a operacional, considerando as premissas das NBC TSP e os procedimentos para registro contábil dos principais fatos relacionados com a administração pública, segundo as regras do PCASP. 


\subsection{Indicadores sociais e evidenciação}

A convergência da contabilidade brasileira a um padrão internacional tem como objetivo aumentar a transparência na evidenciação do uso dos recursos públicos e a responsabilidade fiscal, criando mecanismos que auxiliem os cidadãos no controle social. Cruz (2010) afirma que uma gestão transparente tem como principais características o acesso a informações compreensíveis para todo o cidadão e a abertura para a sua participação (controle social).

Pesquisas têm buscado analisar o nível de evidenciação dos entes públicos, bem como a relação com características econômicas e sociais desses entes.

Os indicadores mais utilizados em pesquisas nacionais com o intuito de refletir as condições econômicas e sociais dos entes públicos são: Receita Orçamentária, Transferências de Recursos da União, PIB per capita, Índice de Desenvolvimento Humano (IDH), Índice Firjan de Desenvolvimento Municipal, Índice Firjan de Gestão Fiscal e Taxa de Alfabetização. Algumas pesquisas utilizam também variáveis relacionadas ao tamanho do ente, como população.

Receita orçamentária é o montante total de impostos, taxas, contribuições e outras fontes recolhidos ao ente e incorporados ao seu patrimônio, que serve para custear as despesas públicas e as necessidades de investimentos. De acordo com Cruz (2010) a receita orçamentária representa a capacidade de geração de receitas do ente público.

As transferências de recursos provenientes da união, independentemente de serem de natureza legal ou voluntária, propiciam melhores condições econômicas aos entes beneficiados. Assim, pressupõe-se que municípios favorecidos com volumes maiores de recursos repassados pela União tenderiam a divulgar mais informações, inclusive como uma forma de prestação de contas em relação aos recursos recebidos (Avelino, 2013).

O PIB per capita é um indicador do nível de atividade econômica, sendo calculado pelo valor total dos bens e serviços produzidos (produto interno bruto) dividido pela quantidade de habitantes de uma região (Cruz, 2010). O PIB é a soma de todos os bens produzidos, e quanto maior o PIB, maior o nível de desenvolvimento, podendo-se classificar, por exemplo, os países em pobres, ricos ou em desenvolvimento, e se espera que entes públicos mais desenvolvidos apresentem maior índice de transparência de sua gestão, e consequentemente, maior nível de divulgação de informações.

Segundo o Programa das Nações Unidas para o Desenvolvimento no Brasil, o Índice de Desenvolvimento Humano (IDH) é uma medida resumida do progresso no longo prazo em três dimensões básicas do desenvolvimento humano: renda, educação e saúde. O objetivo da criação do IDH foi o de oferecer um contraponto a outro indicador muito utilizado, o Produto Interno Bruto (PIB) per capita, que considera apenas a dimensão econômica do desenvolvimento (Santos, 2013). O IDH foi analisado em pesquisas como as de Cruz, Silva e Santos (2009), Cruz (2010) e Avelino (2013), levando em consideração que, entes públicos com maior índice de desenvolvimento apresentam maior transparência de sua gestão.

O Índice Firjan de Desenvolvimento Municipal (IFDM) é um índice desenvolvido pelo Sistema FIRJAN, cujo objetivo é acompanhar o desenvolvimento humano, econômico e social de todos os municípios brasileiros, apresentando uma série anual com base em dados oficiais. O IFDM considera, com igual ponderação, as três principais áreas de desenvolvimento humano, a saber, emprego, renda, educação e saúde. O IFDM varia entre 0 e 1, sendo que quanto mais próximo de 1, maior o nível de desenvolvimento do município (Cruz, 2010).

Já o Índice Firjan de Gestão Fiscal (IFGF), segundo Santos (2013), foi desenvolvido para contribuir com uma gestão pública eficiente e democrática, que tem como objetivo estimular a cultura da responsabilidade administrativa, por meio de indicadores que possibilitem o aperfeiçoamento das decisões quanto à alocação dos recursos públicos, bem como maior controle social da gestão fiscal dos municípios. Composto por cinco indicadores: Receita Própria, Pessoal, Investimentos, Liquidez e Custo da Dívida, o índice tem como base de 


\section{Mariana Camilla Coelho Silva Castro, Jacqueline Veneroso Alves da Cunha, Jorge Eduardo Scarpin \& José}

Roberto de Souza Francisco.

dados as estatísticas oficiais disponibilizadas anualmente pela Secretaria do Tesouro Nacional, constituídas por informações orçamentárias e patrimoniais prestadas pelos próprios municípios.

A taxa de alfabetização, segundo PNUD (2012), é representada pelo percentual de pessoas acima de 15 anos de idade que são alfabetizadas, ou seja, que sabem ler e escrever pelo menos um bilhete simples, e indica o nível educacional de uma população. Cruz et al. (2009) utilizaram essa variável em sua pesquisa, considerando que a taxa de alfabetização tem relação positiva com a transparência do ente público.

O tamanho do ente geralmente é relacionado com a população, ou seja, o seu número de habitantes. Nos estudos de Lock (2003) e Cruz et al. (2009) os autores assumiram que municípios com maior população tendem a apresentar maior transparência de sua gestão, já Santos (2013) e Avelino (2013) consideram que municípios maiores tendem a divulgar mais informações contábeis devido ao elevado número de cidadãos que tenderia a exercer maior pressão sobre o ente público.

No estudo realizado por Cruz (2010) a autora buscou, dentre outros objetivos, agrupar os municípios da amostra de acordo com o desempenho observado no nível de divulgação das informações concernentes à gestão pública. Para isso, foi aplicada a análise de clusters, a partir da qual foi possível agrupar os municípios da amostra em dois grupos: o primeiro composto por municípios com melhor desempenho médio no índice de transparência e também nos indicadores socioeconômicos considerados, contendo a maioria das capitais, dos municípios da região sul e sudeste; já o segundo grupo foi formado por municípios com menores desempenhos no índice de transparência e também nos indicadores socioeconômicos considerados, sendo a maioria dos municípios situados em regiões metropolitanas. Os resultados apontam a formação de grupos distintos levandose em consideração o nível de transparência das informações divulgadas nos portais eletrônicos por parte dos grandes municípios brasileiros bem como suas características socioeconômicas.

\section{Procedimentos Metodológicos}

Quanto aos objetivos, esta pesquisa pode ser classificada como exploratória e descritiva. Esta pesquisa é exploratória, uma vez que tem como objetivo identificar as mudanças trazidas pelo novo cenário de convergência da Contabilidade Pública brasileira aos padrões internacionais e em razão da escassez de estudos abordando as alterações nas Demonstrações Contábeis após a obrigatoriedade de adoção da nova legislação. Conforme Raupp e Beuren (2003) a pesquisa exploratória ocorre quando há pouco conhecimento sobre a temática a ser abordada.

Também pode ser classificada como descritiva, na medida em que busca verificar o nível de disclosure dos Estados brasileiros em relação ao exigido pelas Normas Brasileiras de Contabilidade Aplicadas ao Setor Público. Para Cooper e Schindler (2003) a pesquisa descritiva reflete um estudo estruturado com questões de pesquisa claramente delineadas, que visam: descrever fenômenos ou características associadas com a população-alvo e descobrir associações entre as variáveis.

Quanto à abordagem do problema e aos procedimentos técnicos, ela pode ser classificada, respectivamente, como quantitativa, bibliográfica e documental. A pesquisa quantitativa caracteriza-se pelo emprego de instrumentos estatísticos, tanto na coleta quanto no tratamento dos dados 0 procedimento bibliográfico se caracteriza pela análise de livros, artigos, dissertações e teses com vistas a embasar o estudo apresentado. $O$ procedimento documental envolve a análise da legislação, das normas, e das Demonstrações Contábeis dos entes públicos (Raupp \& Beuren, 2003).

As primeiras NBC TSP (àquela época NBCASP), que entraram em vigor, se tornaram obrigatórias no fim do exercício de 2014 para União, Estados e Municípios. Optou-se, nesta pesquisa, por analisar a adoção das novas normas no âmbito Estadual, compreendendo os 26 Estados brasileiros e o Distrito Federal.

Inicialmente, visando construir 0 índice de disclosure das informações contábeis conforme as exigências estabelecidas pelas NBC TSP e o MCASP, foram analisadas as Demonstrações Contábeis dos 
entes públicos referentes ao período de 2014. As demonstrações foram coletadas em dezembro de 2015 nos websites das Secretarias de Fazenda, Tribunais de Contas e portais de transparência de cada Estado e do Distrito Federal. No período em que os dados foram coletados, a prestação de contas mais atual divulgada pelo estado de Roraima em seu portal do governo era de 2013, com isso, o estado de Roraima não foi considerado na análise. Passando a amostra da pesquisa a ser composta de 25 Estados brasileiros e o Distrito Federal.

A $5^{\text {a }}$ edição do MCASP, que era o manual a ser utilizado para o reconhecimento e divulgação de informações contábeis no exercício de 2014, serviu de referência para identificar se os procedimentos contábeis obrigatórios, de acordo com a nova legislação, haviam sido cumpridos pelos entes públicos. As informações foram analisadas conforme com os itens dispostos na Figura 2.

Os itens foram pontuados de acordo com o seu atendimento ou não. Foi atribuída nota 1, em caso de atendimento, e nota 0 , de não atendimento. Os itens que não se aplicavam a alguma situação foram classificados como N/A (Não Aplicável). Não foi atribuída pontuação em função da qualidade do item divulgado, limitando-se à verificação da divulgação ou não da informação.

Figura 2: Partes do MCASP

\begin{tabular}{|c|c|}
\hline \multirow{7}{*}{$\begin{array}{l}\text { Parte III - Procedimentos } \\
\text { Contábeis Específicos }\end{array}$} & $\begin{array}{l}\text { Fundo de Manutenção e Desenvolvimento da Educação Básica e de Valorização dos } \\
\text { Profissionais da Educação (Fundeb). }\end{array}$ \\
\hline & Parcerias Público-Privadas (PPP). \\
\hline & Operações de Crédito. \\
\hline & Regime Próprio de Previdência Social (RPPS). \\
\hline & Dívida Ativa. \\
\hline & Precatórios. \\
\hline & Consórcios Públicos. \\
\hline $\begin{array}{c}\text { Parte IV - Plano de } \\
\text { Contas Aplicado ao Setor } \\
\text { Público }\end{array}$ & $\begin{array}{l}\text { Adoção do PCASP, segundo o MCASP, detalhado no nível exigido para a consolidação } \\
\text { das contas nacionais. }\end{array}$ \\
\hline \multirow{7}{*}{$\begin{array}{c}\text { Parte V - Demonstrações } \\
\text { Contábeis Aplicadas ao } \\
\text { Setor Público }\end{array}$} & Balanço Orçamentário \\
\hline & Balanço Financeiro \\
\hline & Demonstração das Variações Patrimoniais \\
\hline & Balanço Patrimonial \\
\hline & Demonstração dos Fluxos de Caixa (observância facultativa em 2014) \\
\hline & Demonstração das Mutações do Patrimônio Líquido (observância facultativa em 2014) \\
\hline & Notas Explicativas \\
\hline
\end{tabular}

Fonte: Adaptado do MCASP (STN, 2012).

O índice atribuído a cada ente público analisado foi obtido conforme o ID empregado na pesquisa de Castro e Cunha (2014), conforme segue:

$$
I D=\frac{\sum a}{N-N / A}
$$

Em que: ID = Índice de Disclosure; $N=$ total de critérios; $N / A=n^{0}$ de itens não aplicáveis; e $a=n^{0}$ de itens atendidos. 
Após o cálculo do ID e com base em pesquisas realizadas anteriormente como as de Lock (2003), Cruz et al. (2009), Cruz (2010), Avelino (2013) e Santos (2013) foram selecionados alguns indicadores socioeconômicos com o intuito de identificar a existência de similaridades entre os entes públicos analisados, levando em consideração esses indicadores, bem como o ID alcançado. Os índices socioeconômicos utilizados na pesquisa foram: Receita Orçamentária, Transferências de recursos da União para os Estados, PIB per capita, Índice Firjan de Desenvolvimento Municipal, Índice de Desenvolvimento Humano nas suas três dimensões Educação, Longevidade e Renda, Taxa de Alfabetização e População.

Para isso, foi realizada uma análise de cluster na tentativa de identificar se as características sociais, econômicas, tamanho e o ID dos entes públicos analisados são capazes de agrupá-los com base nas suas similaridades e identificar grupos de estados que sejam mais semelhantes entre si.

Segundo Mingoti (2005), a análise de agrupamentos, também conhecida como análise de conglomerados, classificação ou cluster, tem como objetivo dividir os elementos da amostra em grupos de forma que os elementos pertencentes a um mesmo grupo sejam similares entre si com base em suas características, e os elementos em grupos diferentes sejam heterogêneos em relação a estas mesmas características.

Para iniciar a análise de clusters, definiu-se a medida de dissimilaridade (ou similaridade), bem como a metodologia estatística de clustering a serem utilizadas, a qual se divide, basicamente, em métodos hierárquicos e não hierárquicos.

Como medida de dissimilaridade, utilizou-se a Distância Euclidiana por ser a medida tradicionalmente mais utilizada. Como método hierárquico, utilizou-se o Average Linkage, que em geral, produz melhores partições que os métodos de ligação simples e completa. Para a detecção do número de clusters ideal para a realização da análise, foi realizado o teste de Calinski e Harabasz onde o valor encontrado, chamado de pseudo-F demonstra que, quanto maior o valor, mais distinto é o cluster. E para a análise dos agrupamentos optou-se por utilizar o dendograma, o qual mostra o esquema de aglomeração e a distância entre os grupos. Para tratamento e análise dos dados coletados na pesquisa, utilizou-se o pacote estatístico STATA® versão 12.0.

\section{Resultados e Discussões}

A $5^{a}$ edição do MCASP, como mencionado anteriormente, serviu de referência para verificar o cumprimento ou não das NBC TSP, e foi medido em relação às suas partes III, IV e V que tratam, respectivamente, dos Procedimentos Contábeis Específicos (PCE), do Plano de Contas Aplicado ao Setor Público (PCASP) e das Demonstrações Contábeis Aplicadas ao Setor Público (DCASP), de acordo com a Portaria STN n 634/2013 que estabeleceu para 2014 a observância obrigatória pelos entes públicos desses procedimentos contábeis contidos no MCASP.

O Índice de Disclosure obtido por cada um dos entes públicos analisados é apresentado na Tabela 1.

Tabela 1: Classificação dos entes públicos por Índice de Divulgação

\begin{tabular}{l|c}
\hline \multicolumn{1}{c|}{ Estado } & ID (\%) \\
\hline \multicolumn{1}{c|}{ Bahia } & $92 \%$ \\
\hline Ceará & $92 \%$ \\
\hline Espírito Santo & $92 \%$ \\
\hline Mato Grosso & $92 \%$ \\
\hline Minas Gerais & $92 \%$ \\
\hline Pará & $92 \%$ \\
\hline Pernambuco & $92 \%$ \\
\hline
\end{tabular}




\begin{tabular}{l|c}
\hline \multicolumn{1}{c|}{ Estado } & ID (\%) \\
\hline Rio Grande do Sul & $92 \%$ \\
\hline Rondônia & $92 \%$ \\
\hline Santa Catarina & $92 \%$ \\
\hline São Paulo & $92 \%$ \\
\hline Amazonas & $85 \%$ \\
\hline Rio de Janeiro & $85 \%$ \\
\hline Acre & $77 \%$ \\
\hline Distrito Federal & $77 \%$ \\
\hline Amapá & $75 \%$ \\
\hline Rio Grande do Norte & $69 \%$ \\
\hline Sergipe & $67 \%$ \\
\hline Tocantins & $67 \%$ \\
\hline Alagoas & $62 \%$ \\
\hline Mato Grosso do Sul & $58 \%$ \\
\hline Paraná & $58 \%$ \\
\hline Piauí & $58 \%$ \\
\hline Maranhão & $50 \%$ \\
\hline Goiás & $42 \%$ \\
\hline Paraíba & $42 \%$ \\
\hline
\end{tabular}

Fonte: Elaborada pelos autores

Ao analisar o ID obtido pelos entes públicos pode-se perceber que nenhum deles atendeu na totalidade as exigências estabelecidas pelas NBC TSP e pelo MCASP. O maior índice de divulgação atingiu o patamar de $92 \%$. Dentre esses estados, temos representantes das cinco regiões do país, com três estados da região nordeste e da região sudeste, dois das regiões norte e sul e um representante da região centro oeste. Essa faixa percentual foi a que mais teve representantes, 11 estados no total.

No outro extremo da tabela, seis estados apresentaram um ID menor que 60\%, Mato Grosso do Sul, Paraná, Piauí, Maranhão, Goiás e Paraíba, os dois últimos divulgaram apenas $42 \%$ das informações conforme as exigências da nova regulamentação, ficando muito aquém do esperado em nível de divulgação. Dentre os estados com os piores ID três são da região nordestes, dois da região centro-oeste e um da região sul. 0 pressuposto teórico é que entes públicos com maiores níveis econômicos e sociais tendem a divulgar mais informações, contudo, o resultado apresentado pelo estado do Paraná vai de encontro a esse pressuposto, uma vez que está entre os estados mais bem classificados em relação aos índices econômicos e sociais, mas deixou de divulgar suas informações contábeis conforme as exigências das NBC TSP, principalmente em relação à utilização do PCASP e da divulgação das DCASP conforme o MCASP.

Quando levados em consideração os entes públicos como um todo, obteve-se uma média de divulgação de itens obrigatórios conforme as NBC TSP de 76\%, demonstrando que os Estados brasileiros e 0 Distrito Federal ainda têm muito que evoluir em termos de divulgação para atender ao que é exigido pela legislação e fornecer informações claras e de qualidade para que o contribuinte possa realizar o controle social através das demonstrações contábeis divulgadas.

Para a realização da análise de cluster, utilizaram-se como variáveis aglutinadoras as características sociais, econômicas, o tamanho e o ID dos entes públicos analisados. A análise de cluster foi utilizada com 0 intuito de agrupar os estados com base nas características que cada um deles possui, de forma que dentro dos grupos formados estejam aqueles estados com as características mais semelhantes, ou seja, verificar tendências com bases nos parâmetros avaliados e nas respectivas divulgações.

Primeiramente, foi realizado um teste com o intuito de verificar quantos clusters seriam indicados utilizar na análise. Para isso, foi realizado o teste de Calinski e Harabasz onde seu índice pseudo-F indicou que o ideal 
seria a utilização de 14 grupos. Com base nesse resultado foi gerado o dendograma, apresentado na Figura 3 , o qual apresenta o esquema de aglomeração e a distância entre os grupos formados.

Figura 3: Dendograma da formação da Análise de Cluster (14 grupos)

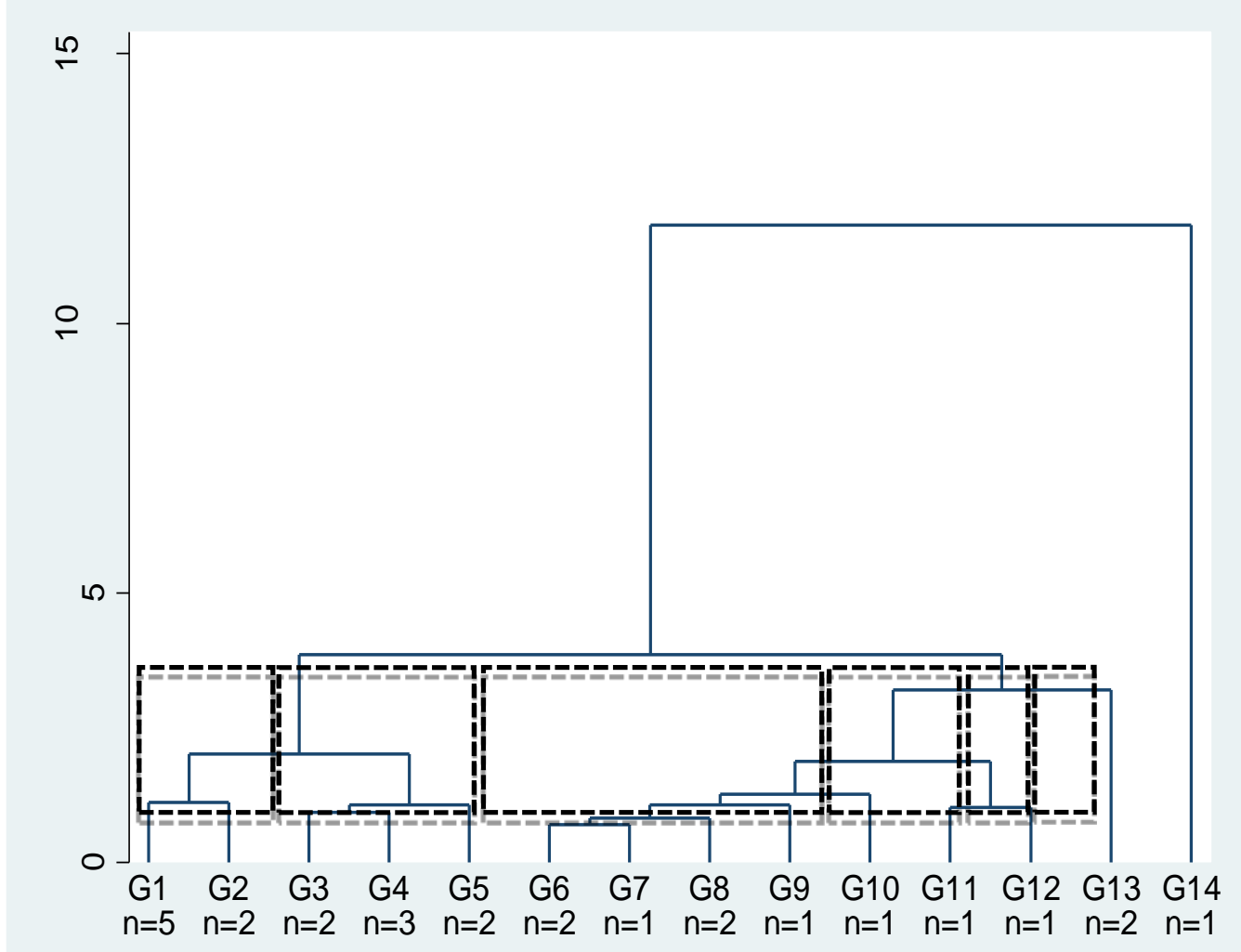

Fonte: Elaborado pelos autores com base nos dados da pesquisa.

Os 14 grupos formados, conforme demonstrado no dendograma, quando aumentada a medida de dissimilaridade, podem ser reagrupados em 6 novos grupos (quadrados tracejados) conforme suas características e similaridades, de modo a simplificar a análise. Os estados estão distribuídos nos grupos conforme os dados apresentados na Figura 4.

Figura 4: Componente dos Clusters

\begin{tabular}{|l|l|}
\hline Agrupamento & \multicolumn{1}{|c|}{ Estado } \\
\hline \multirow{4}{*}{ Grupo 1 } & Acre \\
\cline { 2 - 2 } & Amapá \\
\cline { 2 - 2 } & Amazonas \\
\cline { 2 - 2 } & Rondônia \\
\cline { 2 - 2 } & Tocantins \\
\cline { 2 - 2 } & Pernambuco \\
\cline { 2 - 2 } & Rio Grande do Norte \\
\hline \multirow{5}{*}{ Grupo 2 } & Alagoas \\
\cline { 2 - 2 } & Maranhão \\
\cline { 2 - 2 } & Bahia \\
\cline { 2 - 2 } & Ceará \\
\cline { 2 - 2 } & Piauí \\
\cline { 2 - 2 } & Sergipe \\
\cline { 2 - 2 } & Pará \\
\hline
\end{tabular}




\begin{tabular}{|l|l|}
\hline Agrupamento & \multicolumn{1}{|c|}{ Estado } \\
\hline \multirow{4}{*}{ Grupo 3 } & Espírito Santo \\
\cline { 2 - 2 } & Minas Gerais \\
\cline { 2 - 2 } & Mato Grosso \\
\cline { 2 - 2 } & Goiás \\
\cline { 2 - 2 } & Rio Grande do Sul \\
\cline { 2 - 2 } & Paraná \\
\cline { 2 - 2 } & Paraíba \\
\hline \multirow{2}{*}{ Grupo 4 } & Mato Grosso do Sul \\
\cline { 2 - 2 } & Santa Catarina \\
\hline \multirow{2}{*}{ Grupo 5 } & Rio de Janeiro \\
\cline { 2 - 2 } & São Paulo \\
\hline Grupo 6 & Distrito Federal \\
\hline
\end{tabular}

Fonte: Elaborado pelos autores.

De acordo com a classificação dos entes públicos por região, o grupo 1 é formado principalmente por estados da região norte, dentre os sete componentes do grupo, cinco são da região norte e dois da região nordeste, demonstrando que as características regionais os aproximam, ao mesmo tempo que os afasta dos demais estados que compõe os outros grupos. 0 grupo 2 é formado prioritariamente por estados da região nordeste, onde seis de seus componentes são da região nordeste e um da região norte. $O$ único estado dessas duas regiões que não se encontra nos grupos 1 e 2 é a Paraíba.

O grupo 3 se mostra o mais heterogêneo, com dois representantes da região sudeste (Espírito Santo e Minas Gerais), dois da região centro-oeste (Mato Grosso e Goiás), dois da região sul (Rio Grande do Sul e Paraná) e a Paraíba como única representante da região nordeste.

O grupo 4 é formado por Mato Grosso do Sul e Santa Catarina. $O$ grupo 5 é formado por dois estados da região sudeste (Rio de Janeiro e São Paulo). E o grupo 6 é formado apenas pelo Distrito Federal, demonstrando que suas características são únicas e que, portanto, ele não pode ser relacionado aos demais estados.

Ao aumentar o grau de dissimilaridade representado no dendograma da Figura 3, com o intuito de formar 6 grupos conforme demonstrado na Figura 4, originou-se o dendograma apresentado na Figura 5. 
Figura 5: Dendograma da formação da Análise de Cluster (6 grupos)

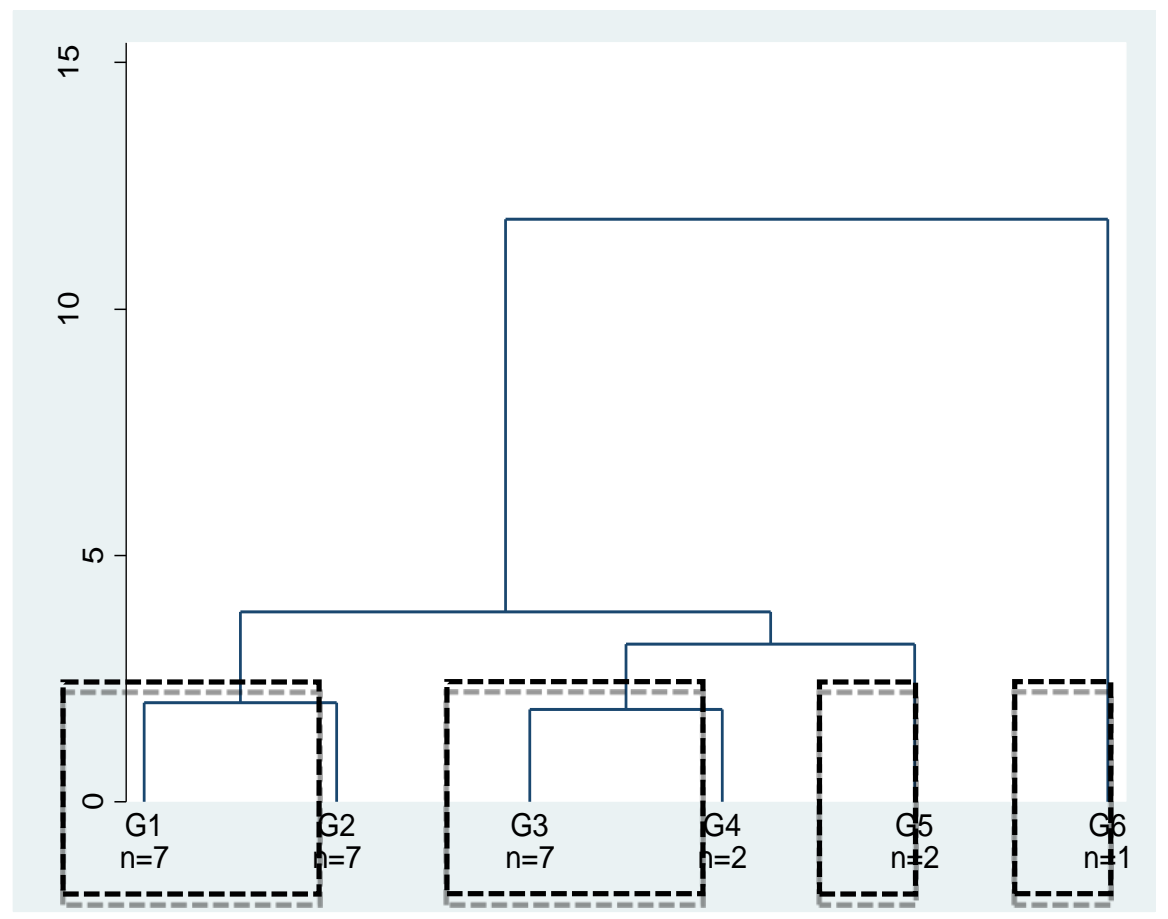

Fonte: Elaborado pelos autores com base nos dados da pesquisa.

Aumentando-se, mais uma vez, a medida de dissimilaridade no dendograma (quadros tracejados), pode-se observar que os grupos 1 e 2 estão mais próximos entre si e mais distantes dos demais grupos com base em suas características. Os grupos 1 e 2, são formados por todos os estados das regiões norte e nordeste, com exceção do estado da Paraíba, demonstrando que, dependendo da região em que o estado se encontra, pode apresentar características mais semelhantes, aproximando-os em relação às suas características econômicas e sociais, bem como em seu índice de disclosure.

Pode-se observar também a formação de um grande grupo aglomerando os grupos 3 e 4, reunindo todos os estados da região sul, todos os estados da região centro oeste, dois estados da região sudeste (Espírito Santo e Minas Gerais) e a Paraíba. O estado da Paraíba se destaca em relação aos demais estados da região norte e nordeste em relação à taxa de alfabetização, talvez esse fato seja um indicativo para seu agrupamento aos estados das regiões centro-oeste, sul e sudeste. Demonstrando que esses estados possuem características semelhantes que os permite serem aglomerados em um mesmo grupo.

Mesmo quando aumentado o grau de dissimilaridade, o grupo formado por São Paulo e Rio de Janeiro e o grupo formado pelo Distrito Federal, grupos 5 e 6 respectivamente, permanecem separados, demonstrando que esses dois grupos possuem características específicas e que, portanto, não podem ser agrupados com os demais.

São Paulo e Rio de Janeiro são os estados que observaram as maiores receitas do exercício de 2014, $\mathrm{R} \$ 209$ e R\$ 82 bilhões, respectivamente, enquanto a média nacional foi de pouco mais de R\$ 32 bilhões. Estão também entre os três estados mais populosos, com aproximadamente 41 e 16 milhões de habitantes, enquanto a média nacional é de 7 milhões, e estão também entre os três estados com a maior taxa de alfabetização.

O Distrito Federal pode ser considerado um outlier uma vez que seu PIB per capita de R $\$ 63.020,02$ e sua Taxa de Alfabetização de 18,57 estão muito acima da média nacional (PIB per capita $=\mathrm{R} \$ 18.588,99 \mathrm{e}$ Taxa de Alfabetização $=7,24$ ), não podendo, com isso, ser agrupado com nenhum dos outros estados. 


\section{Conclusões}

Neste estudo, buscou-se avaliar as similaridades entre os Estados brasileiros e o Distrito Federal em relação à variabilidade das características econômicas e sociais, bem como em relação ao Índice de Disclosure conforme as mudanças trazidas pelas Normas Brasileiras de Contabilidade Aplicadas ao Setor Público (NBC TSP), em consonância com o processo de convergência ao padrão internacional de contabilidade pública.

A amostra da pesquisa foi composta por 25 estados brasileiros e o Distrito Federal, e as características dos entes públicos analisadas foram: Receita Orçamentária, Transferências de recursos da União para os Estados, PIB per capita, Índice Firjan de Desenvolvimento Municipal, Índice de Desenvolvimento Humano nas suas três dimensões Educação, Longevidade e Renda, Taxa de Alfabetização, População e o Índice de Disclosure obtido por cada ente público analisado.

Para atingir os objetivos, primeiramente foi construído o Índice de Disclosure (ID), elaborado com base nas Demonstrações Contábeis referentes ao exercício de 2014. Posteriormente, e com a utilização da técnica multivariada de análise de clusters, os Estados e o Distrito Federal puderam ser aglomerados em quatro grupos de acordo com suas similaridades.

Em relação ao atendimento da nova legislação aplicada à contabilidade do setor público, ao analisar o ID obtido pelos entes públicos pode-se perceber que nenhum deles atendeu na totalidade as exigências estabelecidas, atingindo, no geral, uma média de divulgação de itens obrigatórios de $76 \%$. Isso demonstra que os Estados brasileiros e o Distrito Federal ainda têm muito que evoluir em termos de divulgação para atender ao que é exigido pela legislação e fornecer informações claras e de qualidade para que o contribuinte possa exercer o controle social.

Já os resultados da análise de clusters sugerem que estados da mesma região podem apresentar características mais semelhantes, aproximando-os em relação às suas características econômicas e sociais, bem como em seu índice de divulgação.

O estado da Paraíba se destaca em relação aos demais estados da região norte e nordeste em relação à taxa de alfabetização o que pode explicar sua classificação entre os estados das regiões centro-oeste, sul e sudeste. São Paulo e Rio de Janeiro são os estados que possuem as maiores receitas, as maiores populações e as maiores taxas de alfabetização. O Distrito Federal pode ser considerado um outlier uma vez que seu PIB per capita e sua Taxa de Alfabetização estão muito acima da média nacional.

Ressalta-se que as conclusões se restringem à amostra e ao período analisado. Para pesquisas futuras, sugere-se que sejam agregadas diferentes variáveis ao modelo de investigação, visando 0 aperfeiçoamento da mensuração do índice de disclosure de informações conforme as exigências trazidas pelas NBC TSP, bem como a utilização de períodos posteriores visando analisar a evolução das informações divulgadas pelos entes. Adicionalmente, a análise do ID pode ser realizada de forma regionalizada, à medida que, conforme identificado nesta pesquisa, as características socioeconômicas podem variar entre as regiões do país.

\section{Referências}

Abushamsieh, K., López-Hernández, A. M., \& Ortiz-Rodríguez, D. (2014). The development of public accounting transparency in selected Arab countries. International Review of Administrative Sciences, 80 (2), 421-442.

Avelino, B. C. (2013). Características explicativas do nível de Disclosure Voluntário De Municípios Do Estado De Minas Gerais: Uma Abordagem Sob a Ótica Da Teoria da Divulgação. Dissertação de Mestrado, Universidade Federal de Minas Gerais, Belo Horizonte, MG, Brasil. 
Borges, T. B. (2012). Utilização da informação gerencial no setor público: perspectiva diante das novas normas de contabilidade do setor público. Dissertação de Mestrado, Universidade Federal de Minas Gerais, Belo Horizonte, MG, Brasil.

Castro, M. C. C. S., \& Cunha, J. V. A. (2014, novembro). Convergência às Normas Brasileiras de Contabilidade Aplicadas ao Setor Público: uma Análise dos Entes Públicos Brasileiros. Anais do VI Encontro de Administração Pública da ANPAD, Belo Horizonte, MG, Brasil.

Conselho Federal de Contabilidade (CFC). (2016). Norma Brasileira de Contabilidade, NBC TSP Estrutura Conceitual - Estrutura Conceitual para Elaboração e Divulgação de Informação Contábil de Propósito Geral pelas Entidades do Setor Público.

Cooper, D. R., \& Schindler, P. S. (2003). Métodos de pesquisa em administração. 7. ed. Porto Alegre: Bookman.

Corrêa, M. D. (2014). Relação entre o Nível de Divulgação Ambiental e o Desempenho Ambiental das Empresas Componentes do Índice Bovespa. 2. ed. Porto Alegre: Atlas.

Costa, R. (2012). As Mudanças para a Contabilidade e a Gestão Pública. Caderno Organização Sistêmica, 1(1), 75-88.

Cruvinel, D. P., \& Lima, D. V. (2011). Adoção do Regime de Competência no setor público brasileiro sob a perspectiva das normas brasileiras e internacionais de contabilidade. Revista de Educação e Pesquisa em Contabilidade, 5(3), 69-85.

Cruz, C. F. (2010). Transparência da Gestão Pública Municipal: Referenciais Teóricos e a Situação dos Grandes Municípios Brasileiros. Dissertação de Mestrado, Universidade Federal do Rio de Janeiro, Rio de Janeiro, RJ, Brasil.

Cruz, C. F., Silva, L. M., \& Santos, R. (2009). Transparência da Gestão Fiscal: Um Estudo a partir dos Portais Eletrônicos dos Maiores Municípios do Estado do Rio de Janeiro. Contabilidade, Gestão e Governança - Brasilia, 12(3), 102-115.

Darós, L. L., \& Pereira, A. S. (2012, julho). Análise das Normas Brasileiras Aplicadas ao Setor Público - NBCASP: Mudanças e desafios para a contabilidade pública. Anais do $9^{\circ}$ Congresso USP de Iniciação Científica em Contabilidade, São Paulo, SP, Brasil.

Dantas, J. A., Zendersky, H. C., \& Niyama, J. K. (2004, setembro). A dualidade entre os benefícios do disclosure e a relutância das organizações em aumentar o grau de evidenciação. XXVIII Encontro da ANPAD, Curitiba, PR, Brasil.

Feijó, P. H. (2013) Entendendo as Mudanças: na contabilidade aplicada ao setor público. 1. ed. Brasília: Gestão Pública Ed.

Gava, C. P. (2013). O Processo de Convergência das Normas Brasileiras de Contabilidade Aplicadas ao Setor Público às Normas Internacionais: um estudo sobre a percepção dos profissionais das entidades públicas na região da Amerc em relação às NBCASP. 2013. TCC de Graduação, Universidade do Extremo Sul Catarinense, Criciúma, SC, Brasil.

Lima, D. V., Santana, C. M., \& Guedes, M. A. (2009). As Normas Brasileiras de Contabilidade aplicadas ao setor público e a legislação contábil pública brasileira: uma análise comparativa à luz da teoria contábil. Contabilidade, Gestão e Governança, 12(2), 15-23.

Lock, F. N. (2003). Transparência da gestão municipal através das informações contábeis divulgadas na Internet. Dissertação de Mestrado, Universidade Federal de Pernambuco, Recife, PE, Brasil.

Mingoti, S. A. (2005). Análise de dados através de métodos de estatística multivariada: uma abordagem aplicada. Belo Horizonte: Editora UFMG.

Programa das Nações Unidas para o Desenvolvimento (PNUD). (2012). Atlas do Desenvolvimento Humano no Brasil.

Raupp, F. M., \& Beuren, I. M. (2003). Metodologia da pesquisa aplicável às ciências sociais. In: BEUREN, I. M. (Org.). Como elaborar trabalhos monográficos em Contabilidade: teoria e prática. São Paulo: Atlas.

Salotti, B. M., \& Yamamoto, M. M. (2005). Ensaio sobre a teoria da divulgação. BBR-Brazilian Business Review, 2(1), 53-70.

Salotti, B. M., \& Yamamoto, M. M. (2008). Divulgação voluntária da demonstração dos fluxos de caixa no mercado de capitais Brasileiro. Revista Contabilidade \& Finanças, 19(48), 37-49.

Santos, W. M. (2013). Avaliação do nível de divulgação das informações contábeis nos portais eletrônicos dos municípios do Rio Grande do Norte e a relação com suas características socioeconômicas. Monografia de Graduação, Universidade Federal Rural do Semiárido, Mossoró, RN, Brasil.

Secretaria do Tesouro Nacional (STN). (2012). Plano de Contas Aplicado ao Setor Público.

Secretaria do Tesouro Nacional (STN). (2013). Nota Técnica $n^{\circ}$ 5, de 21 de novembro de 2013. Contabilidade Governamental Tesouro Nacional - Orientações acerca da Portaria STN nº 634, de 19 de novembro de 2013.

Verrecchia, R. E. (2001). Essays on Disclosure. Journal of accounting and economics, 32(1), 97-180. 


\title{
DADOS DOS AUTORES
}

\author{
Mariana Camilla Coelho Silva Castro \\ Doutoranda em Controladoria e Contabilidade pela UFMG. \\ Professora Assistente do Departamento de Finanças e Controladoria da Universidade Federal de Juiz de Fora. \\ Endereço: Rua José Lourenço Kelmer, s/n - Campus Universitário. Bairro São Pedro. \\ CEP: 36.036-900 - Juiz de Fora/MG - Brasil \\ E-mail: maricoelho2000@yahoo.com.br \\ Telefone: (32) 2102-3521
}

\section{Jacqueline Veneroso Alves da Cunha}

Doutora em Ciências Contábeis pela FEA/USP.

Professora Associada do Departamento de Ciências Contábeis da Universidade Federal de Minas Gerais.

Endereço: Av. Antônio Carlos, 6627. Pampulha.

CEP: 31.270-901 - Belo Horizonte/MG - Brasil

E-mail: jvac@ufmg.br

Telefone: (31) 3409-7275

\section{Jorge Eduardo Scarpin}

Doutor em Controladoria e Contabilidade pela FEA/USP.

Professor Adjunto do Departamento de Ciências Contábeis da Universidade Federal do Paraná.

Av. Prefeito Lothário Meissner, 632. Jardim Botânico.

CEP: 80.210-170 - Curitiba/PR - Brasil

E-mail: jorge.scarpin@ufpr.br

Telefones: (41) 3360-4362

\section{José Roberto de Souza Francisco}

Doutor em Administração pela UFMG.

Professor Efetivo do Departamento de Ciências Contábeis da Universidade Federal de Minas Gerais.

Endereço: Av. Antônio Carlos, 6627. Pampulha.

CEP: 31.270-901 - Belo Horizonte/MG - Brasil

E-mail: jroberto@face.ufmg.br

Telefone: (31) 3409-7269 
Mariana Camilla Coelho Silva Castro, Jacqueline Veneroso Alves da Cunha, Jorge Eduardo Scarpin \& José Roberto de Souza Francisco.

\section{Contribuição dos Autores:}

\begin{tabular}{lcccc}
\hline Contribuiç̧ão & $\begin{array}{c}\text { Mariana } \\
\text { Castro }\end{array}$ & $\begin{array}{c}\text { Jacqueline } \\
\text { Cunha }\end{array}$ & $\begin{array}{c}\text { Jorge } \\
\text { Scarpin }\end{array}$ & $\begin{array}{c}\text { José } \\
\text { Francisco }\end{array}$ \\
\hline 1. Concepção do assunto e tema da pesquisa & $\sqrt{ }$ & & & \\
2. Definição do problema de pesquisa & $\sqrt{ }$ & $\sqrt{ }$ & \\
3. Desenvolvimento das hipóteses e constructos da & $\sqrt{ }$ & $\sqrt{ }$ & \\
pesquisa (trabalhos teórico-empíricos) & & & \\
4. Desenvolvimento das proposições teóricas & & & \\
(trabalhos teóricos os ensaios teóricos) & $\sqrt{ }$ & $\sqrt{ }$ & \\
5. Desenvolvimento da plataforma teórica & $\sqrt{ }$ & & \\
6. Delineamento dos procedimentos metodológicos & $\sqrt{ }$ & & \\
7. Processo de coleta de dados & $\sqrt{ }$ & $\sqrt{ }$ & \\
8. Análises estatísticas & $\sqrt{ }$ & & \\
9. Análises e interpretações dos dados coletados & $\sqrt{ }$ & $\sqrt{ }$ & \\
10. Considerações finais ou conclusões da pesquisa & $\sqrt{1 . \text { Revisão crítica do manuscrito }}$ & $\sqrt{ }$ & & \\
12. Redação do manuscrito & & & \\
\hline
\end{tabular}

